\title{
The German NET-Registry: An Audit on the Diagnosis and Therapy of Neuroendocrine Tumors
}

\author{
Ursula Ploeckinger $^{\mathrm{a}}$ Guenter Kloeppel $^{\mathrm{b}}$ Bertram Wiedenmann ${ }^{\mathrm{c}}$ \\ Ruediger Lohmann $^{d}$ and representatives of 21 German NET Centers \\ aDepartment of Hepatology and Gastroenterology, Campus Virchow-Klinikum, Charité-Universitätsmedizin Berlin, \\ Berlin, b Department of Pathology, Universität Schleswig-Holstein, Campus Kiel, Kiel, 'Department of Hepatology \\ and Gastroenterology, Campus Virchow-Klinikum, Charité-Universitätsmedizin Berlin, and d Lohmann and Birkner \\ Health Care Consulting GmbH, Berlin, Germany
}

\section{Key Words}

Neuroendocrine tumor $\cdot$ Diagnosis, neuroendocrine tumor - Treatment, neuroendocrine tumor · NET guidelines, German

\begin{abstract}
Aims: Clinical experience with neuroendocrine tumors (NETs) is difficult to acquire because they are rare and heterogeneous. The impact of guidelines on the care for NETs is not known. The German NET Registry compiled information for Germany pertaining to three questions: who provides care for NET patients; does the care comply with proposed guidelines, and are the results comparable to those described in the literature? Patients and Methods: Between 2004 and 2007 data on 1,263 patients from 21 centers were compiled in a dedicated database. Results: Tumor location, age and sex compared well with published data. Most patients were cared for in centers with more than 100 (47.9\%) or between 20 and 99 patients (46.1\%). Imaging (magnetic resonance tomography, computer tomography, ultrasound) was available for $79 \%$ of the patients, specific laboratory tests for $67 \%$, somatostatin receptor scintigraphy for $56 \%$, and pathology findings for $79 \%$. High-quality pathology re-
\end{abstract}

ports were rare (2\%). Sufficient documentation was mostly found in large centers. Surgery was the first-line therapy in $70.9 \%$, while medical therapy was the second-line therapy in $45.7 \%$ of the patients. Median follow-up was 2.8 (0.4-6.4) and median overall survival was $2.5(0.34-6.3)$ years. Conclusions: Most patients were referred to large specialized centers. Those centers adhered best to published guidelines for NETs. However, there are still significant deficiencies in the documentation of diagnostic results, mainly with regard to pathology reports. Therapeutic strategies were comparable between centers. The data provide a basis for future studies assessing improvements in documentation, diagnosis and treatment of NET.

Copyright $\odot 2009$ S. Karger AG, Basel

\section{Introduction}

Neuroendocrine tumors (NETs) are rare. Data on the epidemiology of NETs have been published [1-8]. A major step forward was the WHO classification of NETs [9], which considered the biological and morphological heterogeneity typical of NETs and introduced a uniform terminology and prognostic stratification. Subsequently, a

\section{KARGER}

Fax +4161306 1234

E-Mail karger@karger.ch

www.karger.com (c) $2009 \mathrm{~S}$. Karger AG, Basel

0028-3835/09/0904-0349\$26.00/0

Accessible online at:

www.karger.com/nen
Ursula Plöckinger

Interdisziplinäres Stoffwechsel-Centrum, Endokrinologie, Diabetes und Stoffwechsel Campus Virchow-Klinikum, Charité-Universitätsmedizin Berlin 1

Augustenburger Platz, DE-13353 Berlin (Germany)

Tel. +49 30450553 552, Fax +49 30450554 944, E-Mail www.stoffwechselcentrum.de 
TNM classification and grading system for NETs were added in 2006 and 2007 [10, 11], which allows risk stratification and prognostic conclusions. Despite this significant progress, evidence-based data from prospective randomized studies reporting diagnostic and therapeutic procedures are rare. In addition, most reports stem from highly specialized centers with interest in NETs. Thus, little is known about the routine care of patients with NETs. As these tumors represent a wide spectrum of rare malignancies, non-specialized centers have limited experience with specific diagnostic procedures and therapies. Moreover, due to the widespread use of advanced imaging techniques, the identification of small, previously undiagnosed tumors has increased and may pose a problem outside specialized centers.

We therefore compiled the available information for Germany from a newly established national NET Registry pertaining to three main questions: (1) who are the care providers for patients with NET, (2) do the diagnostic and therapeutic procedures comply with proposed guidelines, and (3) are the results comparable to those described in the literature?

This article analyses results from 1,263 patients.

\section{Methods}

\section{The German Neuroendocrine Tumor Registry}

The German Neuroendocrine Tumor (NET) Registry is affiliated with the German Endocrine Society. Recruitment of NET centers, defined as any institution that cares for more than 5 NET patients, started in 2003. Institutions are either university or community hospitals. In Germany, information on physicians who care for special diseases is not publicly available. Consequently, 5,903 physicians, identified via published membership lists of the respective medical societies (German Endocrine Society, German Society for Gastrointestinal Diseases and Metabolism, German Society for Hematology and Oncology) were asked to give the number of NET patients cared for and invited to join the German NET Registry, if this number exceeded 5 patients. Five-hundred and ninety physicians (10\%) responded positively. Three hundred and twenty-nine of them met the criteria for participation in the German NET Registry. Finally, by October 2007, 329 centers representing 667 participating physicians were registered. The registry was financed by an unrestricted grant from Novartis Oncology, Germany, providing funds for acquisition of data from 300 patients per year. Novartis had no influence on the setup of the database, data acquisition or data analysis and has no access to raw data.

\section{Data Acquisition}

A dedicated Access database was build by 2 of the authors (UP and RL). The items to be included in a questionnaire were decided upon by 11 specialists experienced in the care of patients with NET (see Acknowledgments). The feasibility and utility of the database was tested in a pre-test in 2003 , including 300 patients.
Necessary modifications, e.g. a reduction in the number of items to be documented, were decided according to the frequency with which each item was found in the patients' files. Any item found in less than $10 \%$ of the patients' files was omitted from the final database. The resulting questionnaire consists of 160 questions. Possible answers are either dichotomized (yes/no) or can be selected using options offered by a drop-down menu.

Two trained study nurses visited each center, analyzed the patients' data files provided by the institution and transferred the data to the database. Between 2004 and 2007, retrospective data documentation for about 300 patients/year resulted in data on 1,263 patients. The centers to be included were chosen according to their location within Germany (north, south, east, west and central). If insufficient numbers of patients were provided by a large center, smaller centers in the vicinity were included until $60 \mathrm{pa}-$ tients/region or a total of 300 patients/year had been documented. Although the inclusion of patients from smaller centers potentially introduces a bias due to different standards in large and small centers, this was considered acceptable since only $6 \%$ of all patients came from medium- to small-sized centers. Data acquisition depended on the positive documentation of items. If for example MEN-1 was documented either as a report of the genetic analysis or stated as diagnosis by the physician, the patient was documented as 'MEN-1-positive'. If, on the other hand, there was no reference to MEN-1, indicating either the absence of MEN-1 or the absent documentation of MEN-1, the patient was documented as 'MEN-1-negative'. The quality of data documentation was checked each year by 2 of the authors on random samples of patients' files. Their results were compared to those in the database. The difference has been minimal so far and $89 \%$ of the data was identical. The main reason for differences was the allocation of repeatedly determined laboratory values to the respective follow-up periods. All data were given a pseudonym. Duplicates from different centers were checked by using date of birth, date of diagnosis, type of tumor, and date of surgery. Any datasets with identical data for all 4 items were thought to belong to 1 patient and the data were merged accordingly. The distribution of tumor locations was comparable for 2006 and 2007. Thus, a representative sample of patients had been accrued and was available for further analysis.

\section{Patient Inclusion}

For retrospective data collection, patients had to be diagnosed with a NET not earlier than January 1, 1999. To be included in the database each center had to present the study to its institutional ethical committee. A positive ethical consent for all of Germany was acquired at the Charité, Berlin. The ethical committee refers to the Declaration of Helsinki and Good Clinical Practice, as well as to the EU regulations [directives 95/46/EC (24/10/1995), 2001/20/EC (04/04/2001) and (EC) 45/2001]. In addition, official consent from the Berlin Commissioner for Data Protection and Freedom of Information was secured. All patients signed an informed consent form.

\section{Statistics}

Normal distribution was tested by Shapiro-Wilks W test. Means \pm SE or median (5-95th percentile) were used as appropriate. For the comparison of independent samples the MannWhitney U test was calculated; for multiple group comparisons the univariate ANOVA test was used. Correlations were tested with a $\chi^{2}$ test, with Fisher's exact $p$ calculated if the numbers were 
Table 1. Patient characteristics: tumor location, age at manifestation and sex

\begin{tabular}{|c|c|c|c|c|c|c|c|c|c|c|c|}
\hline Tumor classification & Number & $\%^{\mathrm{a}}$ & $\begin{array}{l}\text { Age }^{\mathrm{b}} \\
\text { years }\end{array}$ & $\begin{array}{l}\text { 5-95th } \\
\text { percentile }\end{array}$ & Female & $\begin{array}{l}\text { Age } \\
\text { years }\end{array}$ & $\begin{array}{l}\text { 5-95th } \\
\text { percentile }\end{array}$ & Male & Age & $\begin{array}{l}5-95 \text { th } \\
\text { percentile }\end{array}$ & $\mathrm{p}^{\mathrm{c}}$ \\
\hline All & 1,263 & & 57 & $32-76$ & 612 & 56 & $30-76$ & 651 & 59 & $33-75$ & 0.065 \\
\hline Lung & 60 & 4.8 & 59 & $37-75$ & 35 & 57 & $28-72$ & 25 & 63 & $38-75$ & 0.310 \\
\hline Digestive system & 994 & 78.8 & 57 & $31-76$ & 481 & 55 & $30-77$ & 513 & 56 & $32-75$ & 0.217 \\
\hline Esophagus & 7 & 0.6 & 64 & $55-81$ & 7 & 64 & $55-81$ & 0 & - & - & - \\
\hline Stomach & 91 & 7.2 & 60 & $39-77$ & 50 & 57 & $40-76$ & 41 & 61 & $39-77$ & 0.167 \\
\hline Duodenum & 82 & 6.5 & 60 & $40-76$ & 30 & 56 & $32-72$ & 52 & 62 & $41-78$ & 0.035 \\
\hline Pancreas & 392 & 31.0 & 56 & $31-75$ & 190 & 55 & $29-75$ & 202 & 57 & $32-74$ & 0.480 \\
\hline Small intestine & 278 & 22.0 & 59 & $33-76$ & 133 & 59 & $39-79$ & 145 & 57 & $32-74$ & 0.186 \\
\hline Jejunum ${ }^{\mathrm{d}}$ & 19 & 1.5 & 56 & $32-83$ & 12 & 59 & $32-83$ & 7 & 53 & $44-74$ & 0.592 \\
\hline Jejumum/ileum ${ }^{\mathrm{d}}$ & 113 & 8.9 & 58 & $32-77$ & 50 & 59 & $41-79$ & 63 & 56 & $27-72$ & 0.830 \\
\hline Ileum $^{\mathrm{d}}$ & 119 & 9.4 & 59 & $35-76$ & 58 & 59 & $29-80$ & 62 & 60 & $36-75$ & 0.880 \\
\hline Ileum/cecum ${ }^{\mathrm{d}}$ & 27 & 2.1 & 63 & $31-72$ & 13 & 60 & $39-72$ & 14 & 63 & $26-82$ & 0.830 \\
\hline Colon and rectum & 144 & 11.4 & 54 & $21-76$ & 78 & 54 & $21-78$ & 66 & 56 & $20-73$ & 0.503 \\
\hline Cecum $^{\mathrm{e}}$ & 20 & 1.6 & 61 & $29-82$ & 13 & 63 & $44-85$ & 7 & 59 & $13-71$ & 0.536 \\
\hline Appendix ${ }^{\mathrm{e}}$ & 40 & 3.2 & 39 & $16-73$ & 22 & 34 & $15-70$ & 18 & 51 & $16-74$ & 0.172 \\
\hline Ascending colon ${ }^{\mathrm{e}}$ & 3 & 0.2 & 50 & $45-75$ & 3 & 50 & $45-75$ & 0 & - & - & - \\
\hline Colon $^{\mathrm{e}, \mathrm{f}}$ & 13 & 1.0 & 57 & $36-73$ & 7 & 57 & $36-73$ & 6 & 57 & $43-63$ & 0.945 \\
\hline Sigmoid colon and rectum ${ }^{\mathrm{e}}$ & 34 & 2.8 & 57 & $30-76$ & 15 & 55 & $37-79$ & 19 & 19 & $27-76$ & 0.973 \\
\hline Rectum $^{\mathrm{e}}$ & 34 & 2.7 & 57 & $33-79$ & 18 & 55 & $22-83$ & 16 & 60 & $33-79$ & 0.695 \\
\hline Cancer of unkown primary & 172 & 13.6 & 58 & $37-75$ & 82 & 56 & $34-73$ & 90 & 60 & $39-75$ & 0.042 \\
\hline Location not indicated & 34 & 2.7 & 52 & $26-74$ & 14 & 52 & $26-79$ & 22 & 52 & $31-66$ & 0.753 \\
\hline \multicolumn{12}{|l|}{${ }^{a}$ Percent of all tumors. } \\
\hline
\end{tabular}

$<7$. Survival analysis was performed according to Kaplan-Meier statistics. Differences were considered significant if $\mathrm{p}<0.05$. Statistical analysis was performed using STATISTICA 6.0 on Windows XP Professional 2002.

\section{Results}

\section{Patient and Tumor Characteristics}

In order to enable a comparison with published data, we describe the characteristics of the patients and their tumors. 1,263 patients [651 (51.5\%) male] were documented. Sex, age and tumor location are given in table 1. The distribution of the tumors was: digestive system 78.8\%; cancer of unknown primary (CUP) $13.6 \%$; lung $4.8 \%$, and tumor location was not documented in $2.8 \%$.

\section{Sex and Age Distribution}

The sex distribution was equal for all tumors or subgroups thereof (table 1). The median age was 57 (32-76) years. The age was comparable for patients with known location or unknown location of the primary (CUP), and for patients whose tumor location was not documented. Subgroup analysis revealed a significant earlier age at diagnosis for female patients with duodenal tumors ( $\mathrm{p}=$ 0.035 ) or CUP ( $p=0.042$; table 1 ). No multiple tumors were documented.

\section{Histopathological Grading}

Proliferation indices were available for 450/1,263 (35.6\%) tumors. Of these 137 (30.4\%) were considered benign tumors (G1), 230 (51.1\%) well differentiated carcinomas (G2) and 83 (18.4\%) poorly differentiated carcinomas (G3) according to the WHO classification [9]. Table 2 gives the tumor grades according to tumor location.

\section{Functionality and Location}

Functionality, e.g. a hormone excess syndrome, was documented in 259/1,263 (20.5\%) of the tumors. The sex distribution was equal in functioning tumors, while more female patients had nonfunctioning tumors $(\mathrm{p}=0.009)$. Patients with functioning tumors were significantly younger than those with nonfunctioning tumors $(\mathrm{p}=$ 0.031 ), or those with tumors without documented refer- 
Table 2. Histopathological grading

\begin{tabular}{lrccc}
\hline Tumor location & All & Grade 1 & Grade 2 & Grade 3 \\
\hline Lung & 20 & 5 & 12 & 3 \\
Esophagus & 3 & 0 & 0 & 3 \\
Stomach & 31 & 11 & 19 & 1 \\
Duodenum & 21 & 9 & 11 & 1 \\
Pancreas & 154 & 38 & 88 & 28 \\
Small intestine & 105 & 46 & 47 & 12 \\
Colon & 47 & 16 & 17 & 14 \\
CUP & 60 & 10 & 30 & 20 \\
Location n.i. & 9 & 2 & 6 & 1 \\
\hline All & 450 & $137(30.4 \%)$ & $230(51.1 \%)$ & $83(18.4 \%)$ \\
\hline
\end{tabular}

n.i. = Not indicated.

Table 3. Functioning tumors

\begin{tabular}{|c|c|c|c|c|c|c|c|c|c|c|c|}
\hline & Number & $\%^{\mathrm{a}}$ & $\begin{array}{l}\text { Age }^{\mathrm{b}} \\
\text { years }\end{array}$ & $\begin{array}{l}5-95 \text { th } \\
\text { percentile }\end{array}$ & Female & $\begin{array}{l}\text { Age }^{\mathrm{b}} \\
\text { years }\end{array}$ & $\begin{array}{l}5-95 \text { th } \\
\text { percentile }\end{array}$ & Male & $\begin{array}{l}\text { Age }^{\mathrm{b}} \\
\text { years }\end{array}$ & $\begin{array}{l}5-95 \text { th } \\
\text { percentile }\end{array}$ & $\mathrm{p}^{\mathrm{c}}$ \\
\hline All patients & 1,263 & & 57 & $32-76$ & 612 & 56 & $30-76$ & 651 & 59 & $33-75$ & 0.065 \\
\hline Functioning tumors & 259 & 20.5 & 53 & $32-75$ & $127(49 \%)$ & 54 & $34-77$ & $132(51 \%)$ & 52 & $31-74$ & 1.000 \\
\hline Carcinoid syndrome & 115 & $44.4^{\mathrm{a}}$ & 57 & $35-74$ & $56(49 \%)$ & 59 & $37-79$ & $59(51 \%)$ & 56 & $27-74$ & 0.547 \\
\hline Insulinoma & 79 & $30.5^{\mathrm{a}}$ & 51 & $30-77$ & $45(57 \%)$ & 53 & $30-77$ & $34(43 \%)$ & 48 & $23-75$ & 0.523 \\
\hline Zollinger-Ellison syndrome & 45 & $17.4^{\mathrm{a}}$ & 51 & $36-74$ & $18(40 \%)$ & 49 & $28-74$ & $27(60 \%)$ & 51 & $36-76$ & 0.378 \\
\hline Glucagonoma & 10 & $3.9^{\mathrm{a}}$ & 10 & $48-64$ & $2(20 \%)$ & 47 & $43-50$ & $8(80 \%)$ & 48 & $35-64$ & 1.000 \\
\hline Somatostatinoma & 3 & $1.2^{\mathrm{a}}$ & 34 & $31-40$ & $1(33 \%)$ & 1 & 34 & $2(67 \%)$ & 36 & $31-40$ & 1.000 \\
\hline VIPoma syndrome & 5 & $1.9^{\mathrm{a}}$ & 51 & $39-66$ & $4(80 \%)$ & 49 & $39-66$ & $1(20 \%)$ & 62 & - & 1.000 \\
\hline Atypical carcinoid syndrome & 1 & $0.4^{\mathrm{a}}$ & 50 & - & $1(100 \%)$ & 50 & - & - & - & - & - \\
\hline Cushing's syndrome & 1 & $0.4^{\mathrm{a}}$ & 45 & - & - & - & - & $1(100 \%)$ & 45 & - & - \\
\hline Non-functioning tumors & 480 & 38.0 & $57^{\mathrm{d}}$ & $30-76$ & $248(52 \%)$ & 56 & $29-76$ & $232(48 \%)$ & 60 & $30-76$ & 0.009 \\
\hline Functionality not indicated & 524 & 41.5 & $59^{\mathrm{e}}$ & $33-75$ & $237(45 \%)$ & 57 & $28-76$ & $287(55 \%)$ & 60 & $36-74$ & 0.241 \\
\hline
\end{tabular}

${ }^{a}$ Individual syndrome as percent of all functioning tumors. ${ }^{\mathrm{b}}$ Age median (5-95th percentile). ${ }^{\mathrm{c}} \mathrm{p}$ for sex distribution (Mann-Whitney U test). ${ }^{\mathrm{d}}$ Age in patients with functioning tumors versus nonfunctioning tumors: $\mathrm{p}=0.031 .{ }^{\mathrm{e}}$ Age in patients with functioning tumors versus unknown functionality: $\mathrm{p}=0.001$.

ence to functionality ( $\mathrm{p}=0.001$; table 3$)$. In patients with a carcinoid syndrome $(\mathrm{n}=115)$ the location of the primary was the small intestine in $77 / 115(67 \%)$, the stomach in $13 / 115$ (11.3\%), the lung in $9 / 115$ (7.8\%), CUP or location not documented in $9 / 115(7.8 \%)$, the appendix in $6 / 115(5.2 \%)$, and the ascending colon in $1 / 115(0.9 \%)$. Eighty-nine percent of the insulinomas were localized in the pancreas: in 1 patient no primary was documented and in 1 the primary was localized in the stomach. The 45 gastrinomas were located in the pancreas $(22 / 45,49 \%)$, duodenum $(13 / 45,29 \%)$, or stomach $(5 / 45,11 \%)$, or were defined as unknown primary (CUP; 5/45, 11\%).

\section{Multiple Endocrine Neoplasia Type 1}

NET associated with multiple endocrine neoplasia type 1 (MEN1) syndrome were documented in 37/1,263
(2.9\%) patients. MEN1 had been excluded in 179/1,263 (14.2\%) patients, while in 1,047/1,263 (82.9\%) patients no reference to MEN1 was made. MEN1 tumors were located in the pancreas $(24 / 37,64.9 \%$; 5 gastrinomas, 2 insulinomas, 1 glucagonoma, 5 nonfunctioning tumors, and 11 tumors not further specified). In 4 tumors (4/37, 10.8\%; 2 gastrinomas, 2 tumors not further specified) the location of the primary was either not known $(n=2)$ or not documented $(\mathrm{n}=2)$. The remaining MEN1 tumor locations $(9 / 37,24.3 \%)$ were the lung $(\mathrm{n}=2)$, stomach (2 gastrinomas), colon (1 nonfunctioning tumor) and small intestine ( $\mathrm{n}=4$, with carcinoid syndrome in 2 ). Patients with MEN1 were more often female $\left(\chi^{2}=6.19, \mathrm{p}=0.023\right)$ and were significantly younger [45.0 (27-66) vs. 58.5 (32.075.0 ) years, $\mathrm{p}=0.0001]$ than were patients in whom MEN1 had been excluded. 
Table 4.

A Center size, number of patients, age and sex distribution

\begin{tabular}{lcllrr}
\hline Center size & $\begin{array}{l}\text { Centers } \\
\mathrm{n}\end{array}$ & $\begin{array}{l}\text { Patients } \\
\mathrm{n}\end{array}$ & $\begin{array}{l}\text { Age } \\
(5 \text { th-95th percentile })\end{array}$ & Female & Male \\
\hline Very large (>100) & 3 & $605(47.9 \%)$ & $56.0(32-74)$ & 291 & 314 \\
Large (20-99) & 12 & $582(46.1 \%)$ & $59.0(30-76)$ & 289 & 293 \\
Medium-size (10-19) & 4 & $58(4.6 \%)$ & $57.0(36-76)$ & 24 & 34 \\
Small (5-9) & 2 & $18(1.4 \%)$ & $48.5(16-83)$ & 8 & 10 \\
\hline All & 21 & $1,263(100.0 \%)$ & $57.0(32-76)$ & 612 & 651 \\
\hline
\end{tabular}

B Center affiliation, number of patients, age and sex distribution

\begin{tabular}{llllrr}
\hline Center affiliation & $\begin{array}{l}\text { Centers } \\
\mathrm{n}\end{array}$ & $\begin{array}{l}\text { Patients } \\
\mathrm{n}\end{array}$ & $\begin{array}{l}\text { Age } \\
(5 \text { th-95th percentile) }\end{array}$ & Female & Male \\
\hline University hospital & 18 & $\begin{array}{c}1,176(93.1 \%) \\
87(6.9 \%)\end{array}$ & $\begin{array}{l}57.0(32-75)^{\mathrm{a}} \\
62.5(36-77)\end{array}$ & 579 & $537^{\mathrm{b}}$ \\
Community hospital & 3 & $1,263(100.0 \%)$ & $57.0(32-76)$ & 612 & 651 \\
\hline All & & & \\
\hline \multicolumn{2}{l}{ a Median age (university hospital vs. community hospital): $\mathrm{p}=0.002}$. \\
b Sex distribution (university hospital vs. community hospital): $\mathrm{p}=0.042$. \\
\hline
\end{tabular}

\section{Additional Malignancies}

Additional malignancies were diagnosed in 138/1,263 (10.9\%) patients. The location of the second malignancy was not documented in 51/138 (37\%), listed as breast cancer $(25 / 138,18.1 \%)$, gastrointestinal malignancy $(21 / 138$, $15.1 \%)$, prostrate cancer $(18 / 138,13.0 \%)$, cervical carcinoma $(9 / 138,6.5 \%)$, carcinoma of the ovaries $(6 / 138,4.3 \%)$, and lymphoma and lung cancer (each $4 / 138,2.9 \%)$. Thirteen tumors were synchronous ( $\mathrm{n}=10 \%)$, while $80 \%$ of the tumors were metachronously diagnosed ( \pm 10 years) in relation to the diagnosis of the NET. The percentage of additional malignancies per specific NET location was $7.9 \%$, for pancreatic tumors, $13.3 \%$ for tumors of the small intestine, and $9 \%$ for NET of the colon, and ranged from 7.3 to $16.3 \%$ for all other locations. The median time between the diagnosis of the additional malignancy and the NET was $-1.42(-22.9 \pm 4.2)$ years, i.e. the NETs were diagnosed 1.42 years after a preexisting malignancy.

\section{Center Characteristics}

To answer the question, as to who are the care providers for patients with NET, we classified NET centers according to the number of patients cared for (table 4A).
Very large ( $>100$ patients), large (20-99 patients), medium-sized (10-19 patients) and small (5-9 patients) centers were distinguished, and their affiliation (table 4B), university [18 centers, 1,176 (93.1\%) patients] versus community hospital [3 centers, 87 (6.9\%) patients], was recorded. Three very large centers cared for $47.9 \%$ of all patients.

\section{Sex and Age Distribution}

Patients cared for in community hospitals were significantly more often male (8.3\%) than female (5.4\%), while the sex distribution was equal in university hospitals $\left(\chi^{2}=4.4, \mathrm{p}=0.042\right)$. Patients cared for in community hospitals were significantly older than those in university hospitals $(\mathrm{p}=0.002$; table 4$)$.

\section{Tumor Location}

There was no selection of tumors by location related to the size of the center. However, differences were seen between university vs. community hospitals $(\mathrm{p}=0.034)$. The relative number of tumors of the small intestine, duodenum and sigma/rectum was lower in university than in community hospitals (fig. 1). Functioning and nonfunctioning tumors were equally distributed between both types of hospital. 


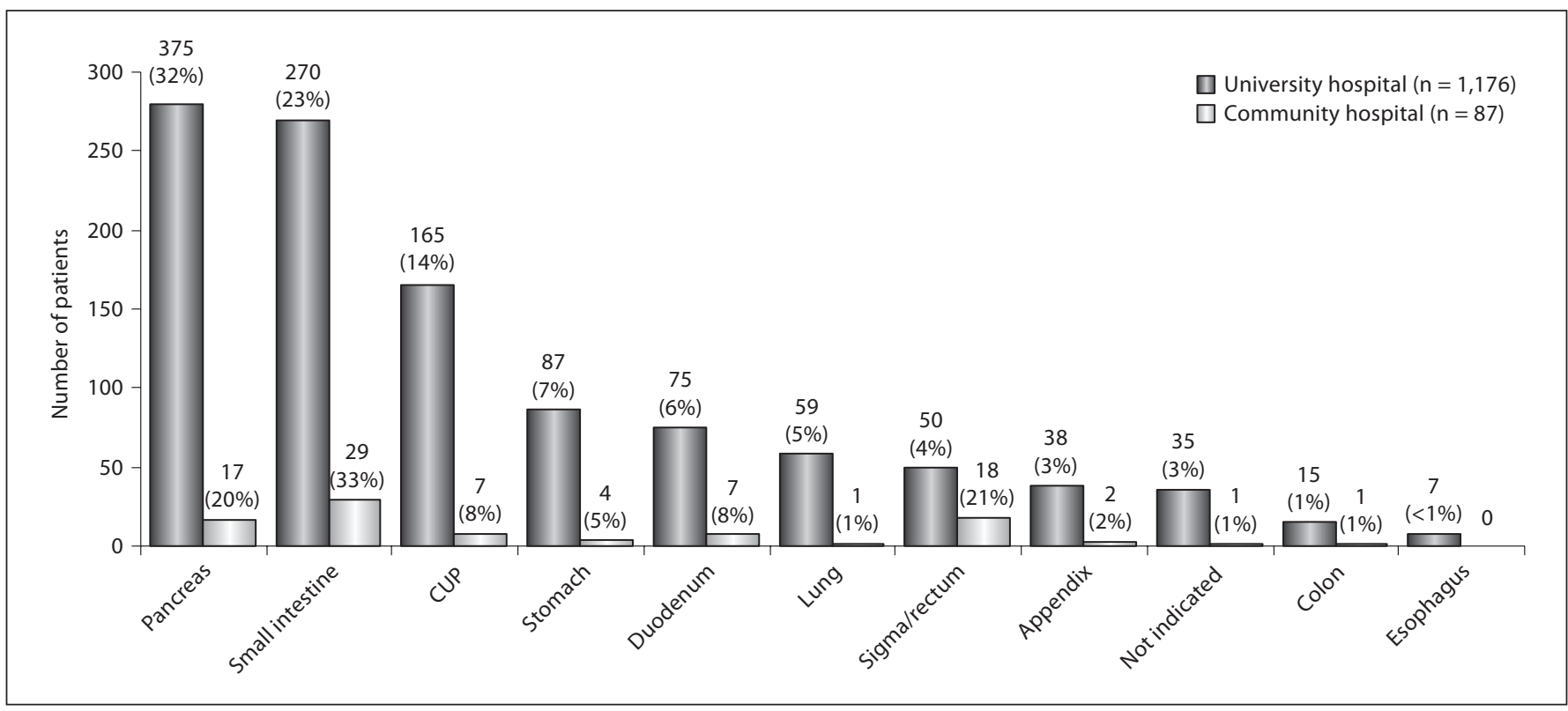

Fig. 1. Center affiliation and location of tumor. The graph specifies the tumor location and gives the number of patients treated according to the size of the centers as well as in percent of patients treated in either university $(\mathrm{n}=1,176)$ or community hospitals $(\mathrm{n}=87)$. While the number of patients treated in community hos-

We can conclude from these data that almost half of the patients were cared for in the 3 largest centers, most were referred to a university hospital and referral was influenced by the location of the NET.

\section{Follow-Up, Diagnostic and Therapeutic Procedures}

Next we analyzed the follow-up and the diagnostic and therapeutic procedures. These data were then related to the location of the tumors to allow a comparison with published consensus guidelines. In a second step we focused on possible differences in the care of these patients related to the size and affiliation of the center.

\section{Follow-Up}

The median follow-up period was $2.8(0.4-6.4)$ years. The median number of visits was $2(1-7)$. Twenty patients (1.6\%) were only seen for a therapeutic intervention and no prior diagnostic or follow-up visit was documented. Excluding these patients did not change the median follow-up period. Follow-up for less than 1, 2 and 3 years was documented in $17.4,18.4$ and $16.8 \%$ of the patients, respectively. Of the remaining patients, $25.5 \%$ were fol- pitals is low compared to university hospitals, the share of patients with neuroendocrine tumors of the small intestine is higher than in university hospitals (i.e. 33.3 vs. $23.0 \%$ ). CUP = Cancer of unknown primary. lowed between 4 and 5 years and $21.9 \%$ for $5-7$ years. One to three visits were documented in $70.2 \%$ of the patients, while $29.8 \%$ had more than 3 (4-11) visits. The length of follow-up correlated with tumor location (univariate ANOVA, $p=0.042$ ), ranging from 2.27 years in patients with tumors of the colon to 3.78 years in those with lung tumors. The length of follow-up and the number of visits per patient were significantly related to the size of the center with the longest follow-up (3.0, 0.3-6.5 years; univariate ANOVA, $\mathrm{p}=0.0001)$, and the highest number of visits $(4,1-8$; univariate ANOVA, $\mathrm{p}<0.001)$ observed in medium-sized centers. While the length of follow-up was unrelated to center affiliation, the number of visits was higher in university hospitals than in community hospitals (2.93 vs. $2.37, \mathrm{p}=0.005)$.

\section{Diagnostic Procedures}

Somatostatin Receptor Scintigraphy

Somatostatin receptor scintigraphy (SRS) was documented in 56.2\% $(710 / 1,263)$ of the patients. Figure 2A gives the percentage of patients with SRS according to tumor location. While the percentage of SRS was higher in patients with tumors of the small intestine than in patients with pancreatic NETs ( 65 vs. $51 \% ; \chi^{2}=13.2$, $\mathrm{p}=$ 


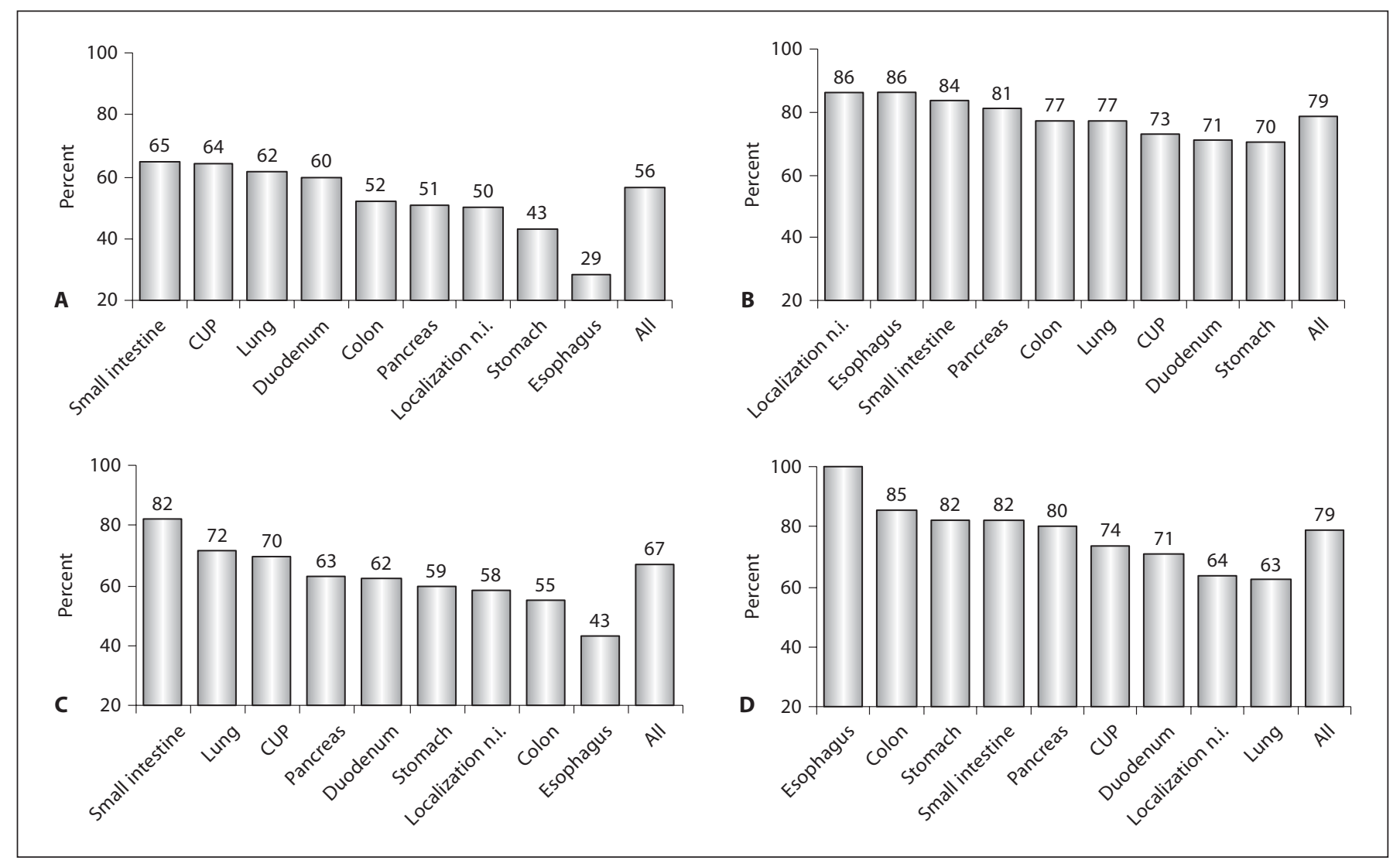

Fig. 2. Percent of patients with somatostatin receptor scintigraphy (A), imaging (B), specific laboratory tests (C) and pathology reports (D) per tumor location. Location n.i. = Tumor location not

$0.0003)$, it was unrelated to documented tumor functionality ( $\chi^{2}$ test, $\mathrm{p}=0.130$ ). The percentage of patients with SRS per center was significantly related to center size (univariate ANOVA, $\mathrm{p}<0.0001$ ), but unrelated to center affiliation, i.e. university vs. community hospital (univariate ANOVA, $\mathrm{p}<0.186$; table 5). The percentage of patients with at least one SRS increased significantly with the length of follow-up [ $\leq 3$ years vs. $>3$ years: $n=$ $549 / 1,023(53.7 \%)$ vs. $161 / 240$ (67.1\%), $\mathrm{p}<0.0001]$ or the number of visits [ $\leq 5$ vs. $>5: \mathrm{n}=593 / 1,091(54.4 \%)$ vs. $\mathrm{n}=$ $117 / 152(77.0 \%), \mathrm{p}<0.0001]$.

\section{Imaging}

Imaging comprised ultrasound and/or computer tomography and/or magnetic resonance imaging. For 993 of the 1,263 (78.6\%) patients results of at least one imaging procedure were available. Figure $2 \mathrm{~B}$ gives the percentage of patients with imaging according to tumor location. The percentage of patients with imaging was highest in documented in patients' files; CUP = cancer of unknown primary. The numbers on top of the columns indicate the number of patients. those without an indicated tumor location (86\%) and lowest in patients with duodenal (71\%) and gastric (70\%) NETs. Documented tumor functionality as well as the size or affiliation of the centers were not related to the frequency of radiological investigations (table 5), as was the length of follow-up ( $\leq 3$ vs. $>3$ years, 78.4 vs. $79.6 \%$; $\mathrm{p}=0.166)$ or the number of visits ( $\leq 5$ vs. $>5,79.3$ vs. $84.2 \% ; \mathrm{p}=0.156)$.

\section{Specific Laboratory Tests}

Specific laboratory tests (CgA, 5-HIAA, serotonin, and/or other tumor markers) were performed at least once in $67.1 \%(847 / 1,263)$ of the patients. Figure $2 \mathrm{C}$ gives the percentage of patients who had laboratory tests related to tumor location. The percentage was highest in tumor locations with a high probability of functionality such as tumors of the small intestine (82\%). Accordingly, it was lower in tumors of the colon (55\%) or esophagus $(43 \%)$. The frequency was independent of the document- 
Table 5. Diagnostic investigations according to center size and affiliation

\begin{tabular}{|c|c|c|c|c|c|c|c|c|}
\hline \multirow[t]{2}{*}{ Diagnostic investigations performed } & \multicolumn{2}{|l|}{ SRS } & \multicolumn{2}{|c|}{ Imaging } & \multicolumn{2}{|c|}{ Biochemistry } & \multicolumn{2}{|c|}{ Pathology } \\
\hline & $\mathrm{n}^{\mathrm{a}}$ & $\%^{\mathrm{b}}$ & $\mathrm{n}^{\mathrm{a}}$ & $\%^{\mathrm{b}}$ & $\mathrm{n}^{\mathrm{a}}$ & $\%^{\mathrm{b}}$ & $\mathrm{n}^{\mathrm{a}}$ & $\%^{\mathrm{b}}$ \\
\hline \multicolumn{9}{|l|}{ Center size } \\
\hline Very large $(n=605)$ & 409 & 67.6 & 471 & 77.9 & 460 & 76.0 & 438 & 72.4 \\
\hline Large $(\mathrm{n}=582)$ & 259 & 44.5 & 461 & 79.7 & 322 & 55.3 & 497 & 85.4 \\
\hline Medium-size $(n=58)$ & 33 & 56.9 & 48 & 82.8 & 48 & 82.8 & 46 & 79.3 \\
\hline Small $(\mathrm{n}=18)$ & 9 & 50.0 & 13 & 72.2 & 17 & 94.4 & 12 & 66.7 \\
\hline $\mathrm{p}$ & \multicolumn{2}{|c|}{$<0.0001$} & \multicolumn{2}{|c|}{0.509} & \multicolumn{2}{|c|}{$<0.0001$} & \multicolumn{2}{|c|}{$<0.0001$} \\
\hline \multicolumn{9}{|l|}{ Center affiliation } \\
\hline University hospitals $(\mathrm{n}=1,176)$ & 667 & 56.7 & 924 & 78.6 & 806 & 68.5 & 918 & 78.1 \\
\hline Community hospitals $(\mathrm{n}=87)$ & 43 & 49.4 & 69 & 79.3 & 41 & 47.1 & 75 & 86.2 \\
\hline $\mathrm{p}$ & \multicolumn{2}{|c|}{0.186} & \multicolumn{2}{|c|}{0.871} & \multicolumn{2}{|c|}{$<0.00004$} & \multicolumn{2}{|c|}{0.074} \\
\hline All $(\mathrm{n}=1,263)$ & 710 & 56.2 & 993 & 78.6 & 847 & 67.1 & 993 & 78.6 \\
\hline
\end{tabular}

ed presence or absence of functionality (univariate ANO$\mathrm{VA}, \mathrm{p}=0.296$ ). It was unrelated to center size and affiliation (table 5), but increased significantly with the length of follow-up [ $\leq 3$ vs. $>3$ years; $n=639 / 1,023(62.5 \%)$ vs. $208 / 240$ (86.7\%); $\mathrm{p}<0.0001]$ and the number of visits [ $\leq 5$ vs. $>5 ; \mathrm{n}=707 / 1,091(64.8 \%)$ vs. $\mathrm{n}=140 / 152$ (92.1\%); $\mathrm{p}<$ $0.0001]$. In patients without therapy $(\mathrm{n}=92)$ and no pathology report $(\mathrm{n}=38 / 92)$ specific hormonal markers were determined in $22(58 \%)$ patients, while $16(42 \%)$ patients had not even a documented determination of biochemical markers $\left(\chi^{2}=0.1, p=0.9224\right)$.

Pathology

At least one pathology report on the primary tumor ( $\mathrm{n}=478,37.8 \%)$, metastases $(\mathrm{n}=250,19.8 \%)$ or both ( $\mathrm{n}=265,21.0 \%)$ were available in the patients' files for $78.6 \%(993 / 1,263)$ of the patients. Figure 2D lists the percentage of patients with pathology reports according to tumor location. A pathology report was significantly more often available in patients without than in those with documented functionality (71.1 vs. $80.8 \%$; univariate ANOVA, $\mathrm{p}=0.023$ ). Center size, but not affiliation, was positively related (univariate ANOVA, $\mathrm{p}<0.0001$ ) to the percentage of patients with available pathology reports (table 5). The percentage of patients with at least one pathology report increased significantly with the length of follow-up ( $\leq 3$ vs. $>3$ years, 80.4 vs. $70.8 \%$; $p<0.0005$ ) or the number of visits ( $\leq 5$ vs. $>5,80.1$ vs. $67.8 \%$; $p<0.0005$ ).
The quality of the pathology report varied widely. Morphology was documented in all cases ( $n=993,100 \%)$; markers of neuroendocrine pathology, i.e. chromogranin A, synaptophysin or specific hormones, in 631/993 (63.5\%); the proliferation index (either Ki67/MIB1 or the number of mitoses per high power field) in 450/993 (45.3\%); angio-invasion or lymphangio-invasion in $106 / 993$ ( $\mathrm{n}=10.7 \%$ ), and the WHO classification of endocrine tumors in 364/933 (36.7\%). Immunohistochemical analysis (IHC) was performed most often using chromogranin A (52.2\%), followed by synaptophysin (47.3\%) and serotonin (8.8\%). Cytokeratin IHC was reported in $10.6 \%$ of all pathology reports. Details on the histopathological grading are given in table 2 .

For each individual patient the sum of these documented items (range 1-5) served as a quality score for the pathology report. Of all pathology reports, $15 \%$ achieved score $1,28.5 \%$ score $2,41.1 \%$ score $3,13.4 \%$ score 4 and only $2 \%$ score 5 . The quality score was significantly correlated with the location of the tumor (Spearmen's $\mathrm{R}=$ $-0.0742, \mathrm{p}<0.05)$. Nonfunctioning tumors scored higher than functioning tumors (Spearman's $\mathrm{R}=-0.169671$, $p<0.05$ ), while neither center size nor affiliation, nor the duration of follow-up or number of visits, or the presence/absence of MEN1 was correlated with the quality score.

In relation to the first therapy, $45.5 \%$ of all pathology reports were documented before, $36.4 \%$ at the occasion of 
Table 6. Patients with two therapies $(\mathrm{n}=574)$ : type of first-line and second-line therapy

\begin{tabular}{lcrrrr}
\hline First-line therapy & $\mathrm{n}^{\mathrm{a}}$ & \multicolumn{4}{l}{ Second-line therapy } \\
\cline { 3 - 6 } & & \multicolumn{1}{l}{ medical } & surgery & irradiation & ablative \\
\hline Surgery & $407(70.9)$ & $186(45.7)^{\mathrm{b}}$ & $160(39.3)$ & $35(8.6)$ & $26(6.4)$ \\
Medical & $144(25.1)$ & $68(47.2)$ & $38(26.4)$ & $25(17.4)$ & $13(9.1)$ \\
Irradiation & $13(2.3)$ & $7(53.9)$ & $2(15.4)$ & $4(30.8)$ & - \\
Ablative & $10(1.7)$ & $8(80.0)$ & $1(10.0)$ & $1(10.0)$ & - \\
\hline All & $574(100)$ & $269(46.8)$ & $201(35.0)$ & $65(11.3)$ & $39(39.0)$ \\
\hline
\end{tabular}

${ }^{a}$ Absolute number of patients for each kind of first therapy followed in parentheses by the percent of patients with this specific therapy as first-line therapy.

b Absolute number of patients with a second therapy after the specific first therapy followed in parentheses by the percent of patients with this specific therapy as secondline therapy. the first therapy and $18 \%$ after the first therapy. Of the 92 patients without therapy, 51 i.e. $55.4 \%$ had available pathology reports.

These data demonstrate clearly that there is broad and competent use of routine imaging techniques in the care of patients with tumor disease. In contrast, information specifically pertaining to NET, i.e. SRS and NET markers, was provided for only half or two thirds of the patients. Moreover, experience, as indicated by the number of patients treated, increased the use of these diagnostic procedures. This is even more valid in the case of pathology reports, which were available in only one third of the patients and were mostly of low quality. As the pathology report provides important information for therapeutic decisions, lack of these data will probably reduce the quality of care.

\section{Therapies}

All therapies were analyzed according to type and sequence of therapy, their relationship to tumor location and center characteristics. These data should provide further insight into the quality of care delivered for NETs.

At least one therapy was documented in 1,171/1,263 $(92.7 \%)$ of the patients, while $92(7.3 \%)$ patients had no documented therapy. Surgery was the first treatment in $908 / 1,171$ (77.5\%), followed by medical therapy $(218 / 1,171$, $18.6 \%)$, radiotherapy $(32 / 1,171,2.7 \%)$ and ablative therapy $(13 / 1,171,1.1 \%)$. A second therapy was documented in 574/1,263 (45.4\%) of the patients. In contrast to the first therapy, medical therapy was offered more often than surgery and the number of patients with radiotherapy or ablative therapy increased significantly $(\mathrm{p}<0.0001$; table 6).

The German NET-Registry
Tumor Location and Functionality

The type of first therapy in relation to tumor location is given in figure 3. Analyzed for the two largest groups of tumors, i.e. pancreas and small intestine, the type of first- and second-line therapy was comparable $(\mathrm{p}=0.317$ and $p=0.963$, respectively). While the type of first therapy was unrelated to tumor functionality $(p=0.250)$, the type of second therapy differed significantly $(\mathrm{p}=$ 0.0216) between patients with functionality compared to those with nonfunctioning tumors (medical therapy 44.1 and $55.4 \%$, surgery 36.4 and $32.9 \%$, radiotherapy 8.5 and $7.0 \%$, and ablative therapy 11.0 and $4.7 \%$, respectively).

\section{Center Size}

Most therapies were reported in very large $(47.1 \%$, $552 / 1,171)$ and large $(47.1 \%, 551 / 1,171)$ centers. Only $4.6 \%$ $(51 / 1,171)$ and $1.4 \%(17 / 1,171)$ of all therapies occurred in medium-sized or small centers. Center size was not correlated with the percentage of patients treated (87.9$94.4 \%)$. Up to 10 therapies/patient were documented (table 7). In $19.6 \%(248 / 1,263)$ patients a therapeutic intervention was performed before any diagnostic procedures. Surgery was the first therapy in $217 / 248(87.5 \%)$ of these patients. Thus, it may be concluded that between 9 and $33 \%$ of tumors were only diagnosed as NETs after the surgical intervention [lung 16/60, (26.7\%), stomach 15/91 (16.5\%), duodenum 18/82 (22\%), pancreas 48/392 (12.2\%), small intestine 44/279 (15.8\%), colon 48/144 (33.3\%), CUP $16 / 172$ (9.3\%), location not indicated 12/36 (33.3\%)]. In these cases peri- and intraoperative procedures specific for NETs might have been missed, with a possible negative impact on their final outcome. 
Fig. 3. Type of first-line therapy and location of the tumor. Location n.i. = Tumor location not documented in patients' files; CUP = cancer of unknown primary.

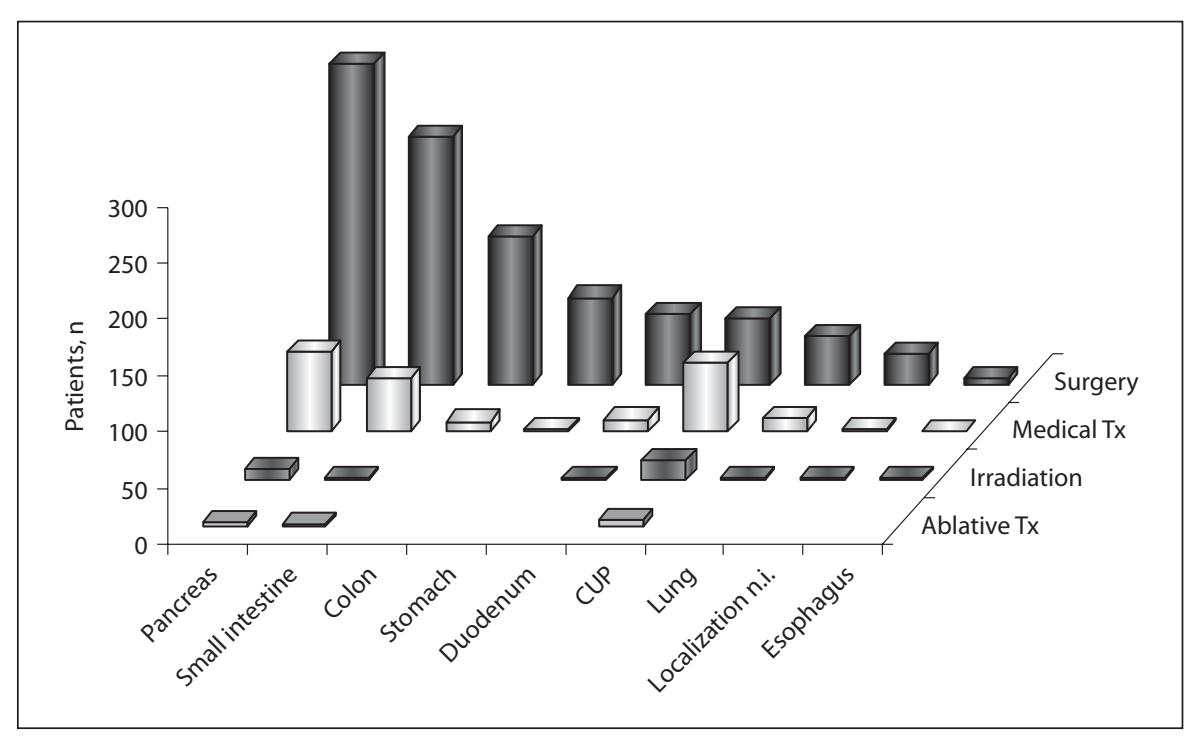

Table 7. Number of therapies and center size in percent of patients treated at these centers

\begin{tabular}{lrrrrl}
\hline \multirow{2}{*}{$\begin{array}{l}\text { Center } \\
\text { size }\end{array}$} & \multicolumn{6}{l}{ Number of therapies } \\
\cline { 2 - 6 } & none & 1 & $2-4$ & $5-7$ & $8-10$ \\
\hline Very large & 8.8 & 91.2 & 43.1 & 6.3 & 0.7 \\
Large & 5.3 & 94.7 & 36.6 & 4.1 & 0.3 \\
Medium & 12.1 & 87.9 & 39.7 & 5.2 & - \\
Small & 5.6 & 94.4 & 33.3 & 5.6 & - \\
\hline
\end{tabular}

\section{Overall Survival and Mortality}

During the observation period 99/1,263 (7.8\%) patients died. The length of follow-up was significantly shorter for survivors than in those who died [2.7 (0.4-6.3) and 4.2 $(1.0-6.9)$ years, $\mathrm{p}=0.0001]$. The median overall survival was $2.5(0.34-6.3)$ years. The overall survival of patients who died was significantly shorter than that of survivors [1.2 (0.1-5) vs. $2.53(0.35-6.26)$ years, $p<0.0001]$. Median survival was not achieved during the observation period. Mortality was not significantly related to tumor location. The death rate per tumor location was highest for colon and esophagus (18.8 and 14.2\%) and lowest for gastric and appendiceal NET (5.5\% and none).

Medium-sized centers had a significantly lower mortality rate than did very large centers (mortality in percent of patients treated: very large centers $9.4 \%$, large centers $6.7 \%$, medium-sized centers $1.7 \%$ and small centers
11.1\%). Three of the 99 deceased patients did not receive any therapy at all. The other 96 patients received up to 8 therapies and the overall number of therapies was significantly higher in those who died than in those who survived [median number (range) of therapies 2 (1-6) and $1(1-5)$; patients who died $(\mathrm{n}=96)$ vs. survivors $(\mathrm{n}=$ $1,175), \mathrm{p}=0.0001]$.

Although the study covered a time interval of 7 years, analysis of therapeutic efficacy is difficult due to the low median follow-up and survival time. The high mortality in very large and small centers may well reflect admission bias, with the most seriously ill patients referred to very large centers or no longer referred from small centers.

\section{Discussion}

\section{Patient and Center Characteristics}

The German NET Registry data were used to evaluate the quality of care of patients with NET in a broad range of institutions. Only patients with a diagnosis after January 1,1999 , were included to avoid a bias resulting from recent diagnostic and technical developments. All data have been collected retrospectively and thus depend on the quality of clinical documentation. Since 2006, with increasing numbers of patients included, the distribution of tumor locations was stable over the whole cohort and thus a representative number of patients have been documented.

A comparison with epidemiological data published in recent years $[12,13]$ is difficult. Most publications ana- 
lyze 'carcinoid tumors', while our definition of a NET includes pancreatic islet cell tumors. The high percentage of poorly differentiated tumors (18\%) does probably not indicate an unusual high prevalence, as grading (available only for one third of the patients) may have been performed preferentially for more malignant tumors, resulting in over-reporting of poorly differentiated tumors. Moreover, a rare inclusion of a mixed tumor, i.e. an adenocarcinoma with partial neuroendocrine differentiation, cannot be excluded. The lack of any patient with multiple tumors is surprising. As all data were collected retrospectively, we cannot decide whether there was indeed no patient with multiple tumors or whether multiple tumors were not documented as such. Two obvious differences to published series are (a) the small number of lung tumors, probably due to a bias among the physicians represented in the NET Registry, and (b) the high percentage of cases of cancer of unknown primary (13.6\%) and tumors without documented location of the primary (2.7\%), most probably due to the retrospective documentation of clinical data. In contrast, most national series refer to national tumor databases that offer a populationbased prospective reporting system for malignancies. These databases however, entail the risk of underreporting grade 1 NETs.

Despite these basic differences our data are rather close to most other epidemiological surveys with respect to tumor location and sex $[3,14,15]$. The higher number of duodenal tumors in male patients has already been noticed $[16,17]$, while no comparable data exist for patients with CUP. The higher number of females with nonfunctioning tumors seen in our data has not been reported so far [18].

There is a minor difference in the age distribution (median 59 years) of the NET Registry patients (patients with pancreatic tumors excluded) compared to the Surveillance, Epidemiology and End Results (SEER) patients (61.4 and 60.9 years, respectively) $[3,13]$ or patients in a smaller national survey (61 years) [15]. If pancreatic tumors are included, the age at diagnosis is further reduced to 57 years. This compared well with a median age of 59 years reported by Yao et al. [19] on pancreatic tumors including hereditary tumor syndromes. In MEN1, NETs are diagnosed at an earlier age. This may explain the younger age at diagnosis of our patients with pancreatic tumors. The same explanation may pertain to the significantly lower age at diagnosis of our patients with functioning tumors compared to nonfunctioning tumors, as a substantial percentage (37\%) of functioning tumors were seen in patients with MEN1.

The German NET-Registry
Additional malignancies ( $11 \%$ of the patients) were clearly underreported compared to the literature [20,21]. Interestingly the NET was diagnosed a median 1.42 years after the first malignancy, while most reports refer to additional malignancy as either synchronous or metachronous. No preference for gastrointestinal malignancies was documented.

Thus, while the overall distribution of tumors is similar to that in other large surveys, subtle differences in the distribution of sex and age occur due to the specificities of the German database, as mentioned above.

The patients were unequally distributed among the different types of hospitals. Almost half of the patients were cared for in 3 large university hospitals with a special interest in NET. Patients in community hospitals were older, possibly due to a preference for a hospital close to home. The higher relative frequency of tumors of the small intestine cared for in community hospitals is probably irrelevant, as $<10 \%$ of all patients with tumors of the small intestine were treated in community hospitals. In contrast, almost one third of the tumors of the sigma/rectum were cared for in community hospitals. Conceivably, these tumors were interpreted as uncomplicated tumors that could be cured by the therapeutic intervention offered, thus preventing the transfer of these patients to a reference center. Several facts underline the role of university hospitals as reference centers: the number of patients was higher, the length of follow-up longer, and the number of visits higher than in community hospitals. These data indicate that most physicians in Germany see NETs as a rare disease that is probably better cared for at a referral center.

\section{Quality of Clinical Data}

Registry data were retrieved from routine clinical files, letters and reports. No hospital had a standardized documentation for patients with NETs. We compared the data quality with the requirements for the diagnosis and treatment of NETd as suggested by the European Neuroendocrine Tumor Society (ENETS) Consensus Recommendations [20, 22-34].

The tumor location was provided for most patients. The term 'location not indicated' is possibly identical to CUP and was used whenever CUP was not specifically stated and no tumor location was given. Excluding lung and pancreas tumors, $25 \%$ of our tumors are classified as CUP, while this is the case in only in $4.95 \%$ of a comparable group of tumors classified as 'digestive, not otherwise specified (NOS)' in the Pan-SEER data [3]. This may be due in part to the differences in data collection. An additional explanation is the insufficient use of specific 
diagnostic tools such as SRS for location of the primary in the German NET Registry. Data for comparison are not available as no epidemiological series refers to the diagnostic tools used. Overall SRS was performed in 56\% of the patients. In very large centers two thirds of the patients had SRS, while only half of the patients in small centers did. This again points to the need for specified centers for the diagnosis and therapy of NET.

\section{Functionality}

The presence or absence of functionality was documented in only $59 \%$ of the patients. Unfortunately, in $41 \%$ neither a positive nor a negative reference documentation of functionality was found. Thus, while we can assume that functionality is documented in patients with functioning tumors, the absence of documented functionality does not exclude a hormonally active syndrome. Smaller, mono-centric surveys give the percent of functioning tumors as 30-40\% [35] for all NETs, between 18 and 30\% has been suggested for tumors of the small intestine [24, 36 ] and up to $68 \%$ for tumors of the pancreas [37]. Thus, the $20 \%$ documented functioning tumors in our series clearly indicates underreporting due to insufficient documentation. Similarly, the diagnosis of MEN1 in patients with pancreatic tumors is biased due to insufficient documentation (82.9\% no reference to diagnose MEN1), with all the possible negative consequences for follow-up and therapeutic decisions.

\section{Diagnostic Procedures}

SRS, the most specific single diagnostic tool $[20,24$, $25,30,38]$, was performed in about half of the patients. Exclusion of tumors without mandatory SRS, as gastric and appendiceal NETs, did not increase the percentage (54\%) of SRS performed. The highest probability for SRS was related to center size and affiliation, and increased with follow-up time and the number of visits. Thus, a patient with 3 years of follow-up and at least 5 visits to a university hospital had a $77 \%$ chance of being evaluated by SRS. Altogether, our data indicate that SRS has been applied less than recommended by current guidelines [19, $20,23-27,30,38,39]$. This cannot be explained by lack of availability or costs, since SRS is easily available in Germany and covered by health insurance.

The situation is slightly better for other imaging modalities. Up to $78 \%$ of the patients had at least one investigation and the number of imaging procedures was not related to center size, affiliation, or to the tumor characteristics. Still, a surprising $22 \%$ of patients had no reference to any imaging procedure documented. Even if we assume that at least one procedure had been performed, results were not available for further reference during follow-up of these patients.

\section{Specific Laboratory Tests}

Specific laboratory tests were documented in about two thirds of the patients and thus clearly less than recommended by the current guidelines $[19,20,23-27,30,38$, 39]. The high number of laboratory tests in patients with functioning tumors indicates that markers were used for confirmation and follow-up. On the other hand, the potential of markers to screen for subclinical functionality or progressive disease was insufficiently used in tumors presumed to be nonfunctioning. The high rate of laboratory tests documented in university hospitals may be related to the long-term follow-up in these centers or to participation in clinical studies. On the other hand, there is no simple explanation for the higher number of laboratory tests per patient performed in medium-sized and small centers compared to large and very large centers.

\section{Imaging}

Overall the number of imaging procedures documented compared favorably with specific neuroendocrine investigations as laboratory tests or SRS. This may be related to a higher familiarity with the workup of tumors in general compared to the specific requirements of NETs.

\section{Pathology Report}

As the diagnosis and therapeutic decisions for NETs are both based on the pathology report, it was a surprising finding that these reports were documented in only $79 \%$ of the patients. It must be assumed that a specimen was either not sent to pathology or pathology reports were not documented. The fact that very large and large centers fared better with respect to a documented pathology report, may be explained by a special interest and higher familiarity with the requirements for decision making. The information provided (tumor morphology, immunohistochemistry, proliferation marker, invasion and WHO classification) was used as an indicator for the quality of the pathology report $[10,11,16]$. The score adds the number of items given per pathology report, indicating the degree of adherence to the recommendations of the ENETS consensus publications [10, 11]. However it does not represent a measure of the quality of the techniques used and does not evaluate the potential to predict the outcome of the disease. A surprising low $2 \%$ met these 5 basic demands and this was independent of center size or affiliation. Interestingly, nonfunctioning tumors 
scored somewhat higher than functioning tumors, supposedly indicating the higher need for in depth pathological characterization in contrast to tumors presenting with a classical neuroendocrine syndrome. In summary, pathological investigations were poorly documented and of low quality. The effect of insufficient pathology data on clinical decisions cannot be underestimated and this is reflected by current guidelines $[10,11,16,20,22,24-27$, 30 ] which recommend the use of pathological data as a basis for therapeutic decisions.

Interestingly more than half of the pathology reports were documented either at or after the first therapy. In these patients the diagnostic confirmation 'neuroendocrine tumor' occurred after the first therapy, indicating that the neuroendocrine nature of the tumor may have been an incidental finding. In addition, the lack of a definite diagnosis before surgical intervention may well have influenced surgical procedures and possibly the longterm outcome of these patients. There are no data in the literature comparing the final outcome of an incidentally diagnosed NET to those with known pathology before surgical intervention. In the German database the number of each tumor entity and the time of follow-up are still too small for such a comparison. Future analysis will be able to provide this information.

\section{Therapy}

The kind and sequence of therapy was comparable to those given by most recommendations, with a preference for surgical therapy followed by medical, ablative or peptide radio-receptor therapy as first therapy, while medical therapy was the preferred first second-line therapy. Neither tumor location nor center size was related to the number of therapies or the sequence of the first 2 therapies. Thus, overall therapeutic schedules were similar all over Germany and complied with consensus recommendations.

\section{Mortality}

Overall, mortality was not significantly related to tumor location. However, it was comparable to data from the literature with the highest death rate occurring in pancreatic tumors, the lowest in appendiceal tumors [3, 19]. Follow-up time was too short to analyze overall survival. Median survival was not achieved. It is, however, interesting that mortality was highest in very large and small centers. This may be due to a referral bias, as patients with a high tumor load or progressive disease were either referred to 1 of the 3 large centers or no longer referred at all, and thus increased the death toll in small centers.

The German NET-Registry

\section{Conclusion}

The German NET Registry provides data on a broad range of NETs and the epidemiological data are, while not identical, at least comparable to large series. We report on the diagnostic and therapeutic procedures for NETs over a wide specter of clinical institutions. Most patients are referred to large specialized centers. The diagnostic tools used differ according to the size of the center, with the highest concordance to consensus recommendations in the 3 very large centers. Still there are significant deficiencies in the documentation of diagnostic results, the most important and obvious being the low quality of available pathology reports. A remarkable observation was the high number of 'incidental diagnosis' indicating that the use of available diagnostic tools is still insufficient. Therapeutic strategies were comparable, yet no final conclusions on therapeutic efficacy can be drawn due to the insufficient time of follow-up. Further data will have to be accrued to answer these questions.

The German NET Registry initiated a prospective data collection. All centers were informed of the guideline recommendations. The comparison of these incoming data with the retrospective analysis will hopefully show an improved management of patients with NETs in Germany.

\section{Appendix}

\section{Participants of the German NET Registry}

Anzinger M, 1. Med. Abteilung, Klinikum Neuperlach, München; Auernhammer C, Med. Klinik u. Poliklinik II, and Hoffmann J, Chirurgische Klinik u. Poliklinik, Klinikum der LudwigMaximilians Universität, Grosshadern, München; Begum N, Klinik f. Chirurgie, Universitätsklinikum Schleswig-Holstein, Campus Lübeck, Lübeck; Bihl H, Nuklearmedizin und PET-Centrum, Katharinenhospital, Stuttgart; Bläker M, Med. Klinik I, Gastroenterologie u. Hepatologie, Universitätsklinikum Hamburg-Eppendorf, Hamburg; Busse F, Medizinische Klinik und Poliklinik III, Endokrinologie, Diabetologie u. Nephrologie, Universitätsklinikum Leipzig, Leipzig; Daum S, Med. Klinik I, Gastroenterologie,Infektiologie, Rheumatologie, Charité-Universitätsmedizin Berlin, Campus Benjamin Franklin, Berlin; Fottner C, Med. Klinik u. Poliklinik I, Schwerpunkt Endokrinologie u. Stoffwechselerkrankungen, and Musholt T, Klinik u. Poliklinik f. Allgemein- u. Abdominalchirurgie, Schwerpunkt Endokrine Chirurgie, Klinikum der Johannes Gutenberg-Universität, Mainz; Frilling A, Klinik f. Allgemein-, Viszeral- u. Transplantationschirurgie, Universitätsklinikum Essen, Essen; Fuchs M, 2. Med. Abt. f. Gastroenterologie, Hepatologie u. gastroenterologische Onkologie, Krankenhaus Bogenhausen, München; Haas S, II. Med. Universitätsklinik, Gastroenterologie, Hepatologie u. Infektiologie, and Niedergethmann M, Chirurgische Universitätsklinik, 
Abt. f. Allgemein-, Viszeral- u. Unfallchirurgie, Universitätsklinikum Mannheim, Mannheim;Isermann B, Med.Universitätsklinik, Innere Medizin I, Abt. f. Endokrinologie u. Stoffwechsel, Universitätsklinikum Heidelberg, Heidelberg; Lammert F, and Zimmer V, Klinikf. Innere Medizin II, Universitätsklinikum d. Saarlandes, Homburg/Saar; Mönig H, Klinik f. Allg. Innere Medizin, I. Med. Klinik, Universitätsklinikum Schleswig-Holstein, Campus Kiel, Kiel; Prinz C, II. Med. Klinik u. Poliklinik, Gastroenterologie, and Vogelsang H, Chirurgische Klinik u. Poliklinik, Klinikum rechts der Isar der Technischen Universität München, München; Raffel A, Klinik f. Allgemein- u. Viszeralchirurgie, and Schmitt M, Med. Klinik u. Poliklinik, Klinik f. Gastroenterologie, Hepatologie u. Infektiologie, Universitätsklinikum Düsseldorf der Heinrich Heine Universität, Düsseldorf; Rinke A, Zentrum f. Innere Medizin, Klinik f. Gastroenterologie, Endokrinologie u. Stoffwechsel, Standort Marburg, Universitätsklinikum Giessen u. Marburg; Schlamp A, Abt. f. Endokrinologie u. Diabetologie, Med. Klinik Innenstadt, Klinikum der Ludwig-Maximilians Universität, München; Stier S, Med. Universitäts-Poliklinik, and Ezziddin S, Klinik für Nuklearmedizin, Zentrum f. Innere Medizin, Med. Klinik u. Poliklinik I - Allg. Innere Medizin, Universitätsklinikum Bonn, Bonn; Bojunga J, Med. Klinik I, Gastroenterologie, Universitätsklinikum d. Johann Wolfgang Goethe Universität, Frankfurt am Main; Wiedenmann B, Med. Klinik m. S. Hepatologie u. Gastroenterologie, and Pascher A, Klinik für Allgemein-, Viszeral- und Transplantationschirurgie, Charité-Universitätsmedizin Berlin, Campus Virchow-Klinikum, Berlin.

\section{Acknowledgements}

For the discussion of databank items we thank Prof. $\mathrm{H}$. Amthauer (Magdeburg), Prof. R. Arnold (Marburg), Prof. H. Dralle (Jena), Prof. W.H. Knapp (Hannover), Prof. K.-J. Klose (Marburg), Prof. J. Langrehr (Berlin), Prof. E. Lehnert (Lübeck), PD Dr. E. Lopez-Haeninnen (Berlin), and Prof. M. Rothmund (Marburg).

\section{References}

1 Godwin JD 2nd: Carcinoid tumors. An analysis of 2,837 cases. Cancer 1975;36:560569.

$>2$ Modlin IM, Sandor A: An analysis of 8305 cases of carcinoid tumors. Cancer 1997;79: 813-829.

$\checkmark 3$ Modlin IM, Lye KD, Kidd M: A 5-decade analysis of 13,715 carcinoid tumors. Cancer 2003;97:934-959.

$\checkmark 4$ Westergaard T, Frisch M, Melbye M: Carcinoid tumors in Denmark 1978-1989 and the risk of subsequent cancers. A populationbased study. Cancer 1995;76:106-109.

$>5$ Levi F, Randimbison L, Franceschi S, La Vecchia C: Descriptive epidemiology of malignant carcinoids in the Swiss Canton of Vaud. Int J Cancer 1993;53:1036-1037.

$\checkmark 6$ Berge T, Linell F: Carcinoid tumours. Frequency in a defined population during a 12year period. Acta Pathol Microbiol Scand A 1976;84:322-330.

$>7$ Hemminki K, Li X: Familial carcinoid tumors and subsequent cancers: a nation-wide epidemiologic study from Sweden. Int J Cancer 2001;94:444-448.

$>8$ Newton JN, Swerdlow AJ, dos Santos Silva IM, Vessey MP, Grahame-Smith DG, Primatesta P, Reynolds DJ: The epidemiology of carcinoid tumours in England and Scotland. Br J Cancer 1994;70:939-942.

9 Solcia E, Klöppel G, Sobin LH: Histological Typing of Endocrine Tumours, ed 2. WHO International Histological Classification of Tumours. Berlin, Springer, 2000.

$\checkmark 10$ Rindi G, Kloppel G, Alhman H, Caplin M, Couvelard A, de Herder WW, Erikssson B, Falchetti A, Falconi M, Komminoth P, Korner M, Lopes JM, McNicol AM, Nilsson O, Perren A, Scarpa A, Scoazec JY, Wieden- mann B: TNM staging of foregut (neuro)endocrine tumors: a consensus proposal including a grading system. Virchows Arch 2006;449:395-401.

11 Rindi G, Kloppel G, Couvelard A, Komminoth P, Korner M, Lopes JM, McNicol AM, Nilsson O, Perren A, Scarpa A, Scoazec JY, Wiedenmann B: TNM staging of midgut and hindgut (neuro)endocrine tumors: a consensus proposal including a grading system. Virchows Arch 2007;451:757-762.

12 Hemminki K, Li X: Incidence trends and risk factors of carcinoid tumors: a nationwide epidemiologic study from Sweden. Cancer 2001;92:2204-2210.

13 Maggard MA, O’Connell JB, Ko CY: Updated population-based review of carcinoid tumors. Ann Surg 2004;240:117-122.

14 Crocetti E, Paci E: Malignant carcinoids in the USA, SEER 1992-1999. An epidemiological study with 6830 cases. Eur J Cancer Prev 2003;12:191-194.

15 Helland SK, Prosch AM, Viste A: Carcinoid tumours in the gastrointestinal tract - a population-based study from Western Norway. Scand J Surg 2006;95:158-161.

16 Kloppel G, Anlauf M: Epidemiology, tumour biology and histopathological classification of neuroendocrine tumours of the gastrointestinal tract. Best Pract Res Clin Gastroenterol 2005;19:507-517.

17 Modlin IM, Champaneria MC, Chan AK, Kidd M: A three-decade analysis of 3,911 small intestinal neuroendocrine tumors: the rapid pace of no progress. Am J Gastroenterol 2007;102:1464-1473.

18 Klimstra DS PA, Öberg K, Komminoth P: Non-Functioning Tumors and Microadenomas. Lyon, IARC Press, 2004.
19 Yao JC, Eisner MP, Leary C, Dagohoy C, Phan A, Rashid A, Hassan M, Evans DB: Population-based study of islet cell carcinoma. Ann Surg Oncol 2007;14:3492-3500.

20 Plockinger U, Couvelard A, Falconi M, Sundin A, Salazar R, Christ E, de Herder WW, Gross D, Knapp WH, Knigge UP, Kulke MH, Pape UF: Consensus guidelines for the management of patients with digestive neuroendocrine tumours: well-differentiated tumour/carcinoma of the appendix and goblet cell carcinoma. Neuroendocrinology 2008; 87:20-30.

21 Tichansky DS, Cagir B, Borrazzo E, Topham A, Palazzo J, Weaver EJ, Lange A, Fry RD: Risk of second cancers in patients with colorectal carcinoids. Dis Colon Rectum 2002;45:91-97.

-22 Ahlman H, Nilsson O, McNicol AM, Ruszniewski P, Niederle B, Ricke J, Jensen R, Kos-Kudla B, Oberg K, O’Connor JM, Pavel ME, Vullierme MP: Poorly-differentiated endocrine carcinomas of midgut and hindgut origin. Neuroendocrinology 2008;87: 40-46.

23 de Herder WW, Niederle B, Scoazec JY, Pauwels S, Kloppel G, Falconi M, Kwekkeboom DJ, Oberg K, Eriksson B, Wiedenmann B, Rindi G, O'Toole D, Ferone D: Well-differentiated pancreatic tumor/carcinoma: insulinoma. Neuroendocrinology 2006;84:183-188.

24 Eriksson B, Kloppel G, Krenning E, Ahlman H, Plockinger U, Wiedenmann B, Arnold R, Auernhammer C, Korner M, Rindi G, Wildi $\mathrm{S}$ : Consensus guidelines for the management of patients with digestive neuroendocrine tumors - well-differentiated jejunal-ileal tumor/carcinoma. Neuroendocrinology 2008; 87:8-19. 
25 Falconi M, Plockinger U, Kwekkeboom DJ, Manfredi R, Korner M, Kvols L, Pape UF, Ricke J, Goretzki PE, Wildi S, Steinmuller T, Oberg K, Scoazec JY: Well-differentiated pancreatic nonfunctioning tumors/carcinoma. Neuroendocrinology 2006;84:196-211.

-26 Jensen RT, Niederle B, Mitry E, Ramage JK, Steinmuller T, Lewington V, Scarpa A, Sundin A, Perren A, Gross D, O'Connor JM, Pauwels S, Kloppel G: Gastrinoma (duodenal and pancreatic). Neuroendocrinology 2006;84:173-182.

27 Jensen RT, Rindi G, Arnold R, Lopes JM, Brandi ML, Bechstein WO, Christ E, Taal BG, Knigge U, Ahlman H, Kwekkeboom DJ, O’Toole D: Well-differentiated duodenal tumor/carcinoma (excluding gastrinomas). Neuroendocrinology 2006;84:165-172.

28 Nilsson O, Van Cutsem E, Delle Fave G, Yao JC, Pavel ME, McNicol AM, Sevilla Garcia MI, Knapp WH, Kelestimur F, Sauvanet A, Pauwels S, Kwekkeboom DJ, Caplin M: Poorly differentiated carcinomas of the foregut (gastric, duodenal and pancreatic). Neuroendocrinology 2006;84:212-215.

29 O’Toole D, Salazar R, Falconi M, Kaltsas G, Couvelard A, de Herder WW, Hyrdel R, Nikou G, Krenning E, Vullierme MP, Caplin M, Jensen R, Eriksson B: Rare functioning pancreatic endocrine tumors. Neuroendocrinology 2006;84:189-195.
30 Ramage JK, Goretzki PE, Manfredi R, Komminoth P, Ferone D, Hyrdel R, Kaltsas G, Kelestimur F, Kvols L, Scoazec JY, Garcia MI, Caplin ME: Consensus guidelines for the management of patients with digestive neuroendocrine tumours: well-differentiated colon and rectum tumour/carcinoma. Neuroendocrinology 2008;87:31-39.

31 Rindi G, de Herder WW, O’Toole D, Wiedenmann B: Consensus guidelines for the management of patients with digestive neuroendocrine tumors: why such guidelines and how we went about It. Neuroendocrinology 2006;84:155-157.

32 Rindi G, de Herder WW, O’Toole D, Wiedenmann B: Consensus guidelines for the management of patients with digestive neuroendocrine tumors: the second event and some final considerations. Neuroendocrinology 2008;87:5-7.

33 Ruszniewski P, Delle Fave G, Cadiot G, Komminoth P, Chung D, Kos-Kudla B, Kianmanesh R, Hochhauser D, Arnold R, Ahlman H, Pauwels S, Kwekkeboom DJ, Rindi G: Well-differentiated gastric tumors/carcinomas. Neuroendocrinology 2006;84:158-164.

34 Steinmuller T, Kianmanesh R, Falconi M, Scarpa A, Taal B, Kwekkeboom DJ, Lopes JM, Perren A, Nikou G, Yao J, Delle Fave GF, O'Toole D: Consensus guidelines for the management of patients with liver metastases from digestive (neuro)endocrine tumors: foregut, midgut, hindgut, and unknown primary. Neuroendocrinology 2008;87:47-62.
35 Pape UF, Bohmig M, Berndt U, Tiling N, Wiedenmann B, Plockinger U: Survival and clinical outcome of patients with neuroendocrine tumors of the gastroenteropancreatic tract in a German referral center. Ann NY Acad Sci 2004;1014:222-233.

- 36 Marshall JB, Bodnarchuk G: Carcinoid tumors of the gut. Our experience over three decades and review of the literature. J Clin Gastroenterol 1993;16:123-129.

37 White TJ, Edney JA, Thompson JS, Karrer FW, Moor BJ: Is there a prognostic difference between functional and nonfunctional islet cell tumors? Am J Surg 1994;168:627-630.

38 Oberg K, Astrup L, Eriksson B, Falkmer SE, Falkmer UG, Gustafsen J, Haglund C, Knigge U, Vatn MH, Valimaki M: Guidelines for the management of gastroenteropancreatic neuroendocrine tumours (including bronchopulmonary and thymic neoplasms). Part II - specific NE tumour types. Acta Oncol 2004;43:626-636.

39 de Herder WW: Tumours of the midgut (jejunum, ileum and ascending colon, including carcinoid syndrome). Best Pract Res Clin Gastroenterol 2005;19:705-715. 